\title{
DEFICIÊNCIAS MOTORAS E GRAVIDADE DE TRAUMAS EM MOTOCICLISTAS VÍTIMAS DE ACIDENTES DE TRÂNSITO*
}

\author{
Eunice Beatriz da Silva Freitas ${ }^{1}$, Inácia Sátiro Xavier de França²
}

\begin{abstract}
RESUMO: Objetivo: relacionar as deficiências motoras adquiridas por motociclistas vítimas de acidentes com a gravidade dos traumas sofridos. Método: estudo quantitativo, descritivo, transversal, realizado a partir de dados secundários extraídos de 439 laudos de acidentes motociclísticos ocorridos no Estado de Pernambuco no ano de 2016. Para classificação da gravidade das lesões, utilizou-se a Condensed Abbreviated Injury Scale e para classificação das deficiências a Classificação Internacional de Funcionalidade, Incapacidade e Saúde. Foi realizada a análise estatística descritiva dos dados. Resultados: a alteração mobilidade das articulações prevaleceu nos motociclistas com gravidade leve $(73,7 \%)$, e as alterações mobilidade óssea, padrão da marcha e força muscular prevaleceram nos motociclistas que apresentaram risco grave - com ameaça a vida (88,9\%, $77,8 \%$ e $33,3 \%$, respectivamente). Conclusão: os achados refletem a magnitude da problemática dos acidentes envolvendo motocicletas, e a necessidade de estratégias preventivas e de promoção da saúde.
\end{abstract}

DESCRITORES: Pessoas com deficiência; Acidentes de trânsito; Motocicletas; Promoção da saúde; Enfermagem.

\section{MOTOR DEFICIENCIES AND TRAUMA SEVERITY IN MOTORCYCLIST VICTIMS OF ROAD TRAFFIC ACCIDENTS}

ABSTRACT: Objective: to relate the motor deficiencies acquired by motorcyclist accident victims to the severity of the traumas suffered. Method: a quantitative, descriptive, cross-sectional study based on secondary data extracted from 439 reports of motorcycle accidents in the state of Pernambuco in 2016. The Condensed Abbreviated Injury Scale was used to assess the severity of the injuries, and the International Classification of Functioning, Disability and Health for the classification. Descriptive statistical analysis of the data was performed. Results: alteration in the mobility of the joints prevailed in the motorcyclists with low severity (73.7\%), and alterations in bone mobility, gait pattern and muscle strength prevailed in motorcyclists who presented a serious, life threatening risk $(88.9 \% 77.8 \%$ and $33.3 \%$, respectively). Conclusion: the findings reflect the magnitude of motorcycle accidents, and the need for preventive strategies and health promotion.

DESCRIPTORS: Disabled people; Traffic-accidents; Motorcycles; Health promotion; Nursing.

\section{DEFICIENCIAS MOTORAS Y GRAVEDAD DE TRAUMAS EN MOTOCICLISTAS VÍCTIMAS DE ACCIDENTES DE TRÁNSITO}

RESUMEN: Objetivo: asociar las deficiencias motoras que adquirieron motociclistas víctimas de accidentes a causa de la gravedad de traumas sufridos. Método: estudio cuantitativo, descriptivo, transversal, que se realizó por medio de datos secundarios recogidos en 439 laudos de accidentes motociclísticos que ocurrieron en el Estado de Pernambuco, en el año de 2016. Para clasificación de la gravedad de las lesiones, se utilizó la Condensed Abbreviated Injury Scale y para clasificación de las deficiencias, la Clasificación Internacional de Funcionalidad, Incapacidad y Salud. Se realizó análisis estadístico descriptivo de los datos. Resultados: la alteración de movilidad de las articulaciones prevaleció en los motociclistas con gravedad baja (73,7\%), y las alteraciones de movilidad ósea, patrón de la marcha y fuerza muscular prevalecieron en los motociclistas que presentaron gran riesgo - con amenaza a la vida (88,9\%, 77,8\% y 33,3\%, respectivamente). Conclusión: los resultados demuestran la magnitud de la problemática de los accidentes con motocicletas, así como la necesidad de estrategias preventivas y de promoción de salud.

DESCRIPTORES: Personas con deficiencia; Accidentes de tránsito; Motocicletas; Promoción de salud; Enfermería.

*Artigo extraído da dissertação de mestrado "Deficiências motoras adquiridas em motociclistas vítimas de acidentes de trânsito". Universidade de Pernambuco/Universidade Estadual da Paraíba, 2018.

${ }^{1}$ Enfermeira. Mestre em Enfermagem. Universidade de Pernambuco e Universidade Estadual da Paraíba. Carpina, PE, Brasil. ${ }^{2}$ Enfermeira. Doutora em Enfermagem. Docente de Enfermagem da Universidade Estadual da Paraíba. Campina Grande, PB, Brasil. 


\section{- INTRODUÇÃO}

Os acidentes de trânsito apresentam-se como fenômeno social de caráter mundial, sendo responsáveis por elevadas taxas de morbidade e mortalidade. Podem causar desde a morte precoce quanto lesões de diferentes gravidades, deixando os vitimados com sequelas que impedem, de forma temporária ou permanente, o prosseguimento de uma vida normal ${ }^{(1)}$. No cenário atual, as ocorrências dos acidentes de trânsito com motocicletas têm se destacado em relação aos acidentes com outros tipos de veículos ${ }^{(2)}$. Com o problema do congestionamento de tráfego, o uso da motocicleta é crescente, como um transporte alternativo e rápido, com maior facilidade de deslocamento, e também por possuir, em termos financeiros, valor reduzido de custo, tanto para aquisição deste tipo de veículo quanto para sua manutenção ${ }^{(3)}$.

Proporcionalmente ao crescente número da frota de motocicletas, as taxas de acidentes de trânsito envolvendo este tipo de transporte também cresceram. Além das altas taxas de mortalidade, os índices de morbidade também são consideráveis, em grande parte, devido à vulnerabilidade deste público, sobretudo em função dos poucos mecanismos protetores ${ }^{(4)}$. Para eles, não existem as proteções utilizadas pelos ocupantes de veículos de quatro rodas, fazendo com que toda a energia gerada durante o impacto do acidente seja absorvida em sua superfície corporal. Como consequência, há ocorrência de vítimas politraumatizadas, fato observado a partir dos atendimentos aos motociclistas em unidades de emergência ${ }^{(5)}$.

Os traumatismos gerados pelos acidentes de trânsito provocam uma série de alterações nos conjuntos dos tecidos dos vitimados, podendo afetar pele, vasos sanguíneos, músculos, ossos, entre outros. A partir dessas lesões, surgem as deficiências relacionadas às funções sensoriais e neuromusculoesqueléticas, comprometendo assim a qualidade de vida das pessoas.

O aumento no quantitativo de acidentes de trânsito com envolvimento dos motociclistas tornouse importante causa de deficiência motora e incapacitação física, em decorrência dos diferentes tipos de lesões e gravidades sofridas durante o trauma ${ }^{(6-7)}$. Ao analisar as indenizações pagas pelo Seguro de Danos Pessoais Causados por Veículos Automotores de Via Terrestre (DPVAT) por Invalidez Permanente nos anos de 2013 e 2014, observa-se que, em 2014, a incidência foi maior justamente nos acidentes envolvendo motocicletas, correspondendo a $80 \%$, e que este tipo de acidente foi também o que apresentou maior crescimento de um ano para o outro, com variação de $39 \%{ }^{(8)}$.

Partindo dessa evidência, este estudo possui o objetivo de relacionar os tipos de deficiências motoras apresentadas por motociclistas vítimas de acidentes de trânsito com a gravidade dos traumas sofridos pelos mesmos.

\section{MÉTODO}

Estudo descritivo, documental, quantitativo com delineamento transversal, desenvolvido a partir do recorte da pesquisa intitulada "Deficiências motoras em motociclistas vítimas de acidentes de trânsito".

A pesquisa foi realizada no Instituto Médico Legal Antônio Persivo Cunha (IML-PE), situado no município de Recife, no Estado de Pernambuco. Este instituto possui como uma de suas atribuições a realização dos exames periciais das lesões corporais em decorrências dos acidentes de trânsito, e a emissão de laudos contendo a classificação do grau de comprometimento corporal, incluindo incapacidades e deficiências.

Foram analisados todos os laudos dos motociclistas vítimas de acidentes de trânsito ocorridos no período de 01 de janeiro de 2016 a 31 de dezembro de 2016. A escolha do ano de 2016 deu-se pela proximidade do mesmo com o período em que foi realizada a coleta dos dados, permitindo assim resultados mais recentes sobre o cenário dos acidentes envolvendo motocicletas.

Foram selecionados para esta pesquisa os laudos em que constavam algum tipo de deficiência motora em decorrência do acidente, considerando como critérios de inclusão: laudos efetuados pelo Instituto Médico Legal de Pernambuco por razões de acidentes de trânsito com motocicletas ocorridos no ano de 2016; ser o condutor da motocicleta no momento do acidente; e laudos com preenchimento 
caligráfico legível. Foram excluídos da amostra os laudos que ainda estavam em seguimento pericial.

A coleta de dados foi realizada durante o mês de julho de 2017, a partir de dados secundários, extraídos dos laudos periciais dos vitimados, utilizando um instrumento para coleta elaborado pelos autores da pesquisa, contendo variáveis relacionadas às características das lesões sofridas, tais como tipo da lesão e segmentos corporais atingidos; bem como a identificação do tipo de deficiência motora adquirida e sua respectiva classificação quanto a ser temporária ou permanente.

Para a análise da gravidade das lesões, foi utilizado o instrumento "Condensed Abbreviated Injury Scale" (CAIS 85), a partir do Manual AIS (Abbreviated Injury Scale). O sistema AIS, criado nos Estados Unidos e publicado em 1971, é instrumento útil na avaliação das vítimas de traumas, permitindo determinar a gravidade das lesões sofridas a partir da classificação de cada lesão corporal específica em um valor de 1 a 5 . O escore 1 corresponde a injúria de gravidade leve, 2 a moderada, 3 a grave que não ameaça a vida, 4 a grave que ameaça a vida, porém com sobrevivência provável e 5 a crítica com sobrevivência incerta ${ }^{(9)}$. Neste estudo, uma vez identificados os tipos de lesões e as regiões corporais traumatizadas nos motociclistas vítimas de acidentes de trânsito, foi realizada a consulta ao mapa CAIS 85 para a classificação da gravidade de cada trauma.

Após a classificação das gravidades dos traumas sofridos pelos motociclistas, foi realizada a classificação dos tipos de deficiências motoras adquiridas utilizando-se a Classificação Internacional de Funcionalidade, Incapacidade e Saúde (CIF), elaborada pela Organização Mundial de Saúde. Essa classificação possui o objetivo de padronizar e unificar condições da saúde e componentes do bemestar relacionados à saúde. Esses domínios são descritos de acordo com a funcionalidade (englobando funções do corpo, participação e atividades) e as incapacidades (englobando deficiências, limitações na participação ou restrições para atividades $)^{(10)}$.

Neste estudo, a CIF foi utilizada considerando as funções neuromusculoesqueléticas e relacionadas com o movimento acometidas pelas deficiências motoras, a saber, alteração na mobilidade das articulações, alteração na mobilidade dos ossos, alteração no padrão da marcha e alteração na força muscular. A alteração na mobilidade das articulações se caracteriza por limitações na amplitude do movimento de pelo menos uma articulação do corpo. A alteração na mobilidade dos ossos inclui redução na amplitude dos movimentos dos ossos que compreendem a cintura escapular, cintura pélvica, ossos cárpicos e ossos társicos. A alteração no padrão da marcha está relacionada à limitação em realizar movimentos como andar e correr de forma independente. E por fim, a alteração na força muscular, caracterizado por déficit na força gerada pela contração de um músculo ou de grupos musculares ${ }^{(10)}$.

Para análise dos dados, foi construído um banco de dados no programa EPI INFO, versão 3.5.2, e após a digitação foi realizada a validação dos dados (dupla digitação para posterior comparação e correção dos valores divergentes). Após a validação, o banco foi exportado para um programa de estatística para realização da análise dos dados.

Foram calculadas as prevalências dos seguimentos corporais atingidos, tipos de lesões e categorias funcionais comprometidas no acidente. Para avaliar a influência da gravidade das lesões da vítima em cada tipo de deficiência motora encontrada, foi aplicado o teste Qui-quadrado para independência. Nos casos em que as suposições do teste Qui-quadrado não foram satisfeitas, aplicou-se o teste Exato de Fisher. Todas as conclusões foram tiradas considerando o intervalo de confiança de 95\%.

Observando os princípios éticos das pesquisas científicas envolvendo seres humanos, o presente estudo foi aprovado pelo Comitê de Ética e Pesquisa da Reitoria da Universidade de Pernambuco, Parecer $\mathrm{n}^{\circ}$ 2.108.062.

\section{- RESULTADOS}

No ano de 2016, foram realizadas 1156 perícias médicas em motociclistas vítimas de acidentes de trânsito pelo Instituto Médico Legal de Pernambuco. Cada um dos laudos foi lido e analisado cuidadosamente, de modo que, ao final, foram identificados 439 laudos periciais que se enquadravam nos critérios de inclusão estabelecidos para esta pesquisa. 
De maneira isolada, verificou-se que os segmentos corporais mais atingidos foram mão (19,4\%, $\mathrm{n}$ $=85)$ perna $(16,6 \%, \mathrm{n}=73)$ e pé $(14,8 \%, \mathrm{n}=65)$ e os segmentos menos atingidos/não atingidos foram: pescoço $(0 \%)$, coluna $(2,3 \%, n=10)$ e quadril $(3,4 \%, n=15)$. Ao serem consideradas as áreas corporais a partir da soma de cada segmento lesionado, percebe-se que os membros inferiores foram os mais comprometidos (271 registros, incluindo coxa, joelho, perna, tornozelo e pé), seguidos dos membros superiores (259 registros, incluindo ombro, braço, antebraço, punho e mão).

Em relação às lesões apresentadas pelos motociclistas e que resultaram em deficiências motoras, o quantitativo total de lesões foi de 545. Isso se explica porque um motociclista pode ter sofrido mais de um tipo diferente de lesão, como pode ser constatado na análise dos segmentos corporais atingidos. No que se refere aos tipos de lesões, verificou-se que, destacadamente, as fraturas fechadas foram as mais comuns $(66,5 \%, n=292)$, seguido da fratura exposta $(19,4 \%, n=85)$ e luxação $(9,1 \%, n=40)$. Os tipos de lesões menos prevalentes foram lesão vascular $(1,4 \%, n=$ seis), entorse $(1,6 \%, n=$ sete) e lesão nervosa $(2,3 \%, \mathrm{n}=10)$.

Considerando os segmentos corporais atingidos e as lesões encontradas, foi realizada a classificação da gravidade dos traumas sofridos pelos motociclistas, utilizando o Condensed Abbreviated Injury Scale (CAIS 85). Observou-se que as lesões de gravidade CAIS $<3$ que não ameaçam a vida, foram as mais prevalentes entre as vítimas, onde a gravidade 2 (moderada) foi a mais comum. Vale salientar que, neste estudo, não se obteve registros de traumas com gravidade CAIS 5 - crítica com sobrevivência incerta. A Tabela 1 apresenta a avaliação das gravidades dos traumas.

Tabela 1 - Avaliação da gravidade do trauma sofrido pelos motociclistas de acordo com o CAIS 85 ( $\mathrm{n}=439$ ). Recife, PE, Brasil, 2016

\begin{tabular}{lcc} 
Fator avaliado & $\mathbf{N}$ & $\%$ \\
\hline Avaliação da gravidade dos traumas em cabeça e pescoço & & \\
\hline Sem lesão & 436 & 99,4 \\
\hline CAIS85 (2) Moderada & 1 & 0,2 \\
\hline CAIS85 (3) Grave - sem ameaça a vida & 1 & 0,2 \\
\hline CAIS85 (4) Grave - com ameaça a vida & 1 & 0,2 \\
\hline Avaliação da gravidade dos traumas em membros e cintura pélvica & & \\
\hline Sem lesão & 2 & 0,5 \\
\hline CAIS85 (1) Leve & 76 & 17,3 \\
\hline CAIS85 (2) Moderada & 234 & 53,3 \\
\hline CAIS85 (3) Grave - sem ameaça a vida & 119 & 27,1 \\
\hline CAIS85 (4) Grave - com ameaça a vida & 8 & 1,8
\end{tabular}

Observa-se que, dos três motociclistas que apresentaram lesões nas regiões da cabeça e pescoço que resultaram em deficiência motora, um apresentou classificação 2 pelo CAIS 85 - gravidade moderada; outro apresentou classificação 3, que corresponde aos traumatismos graves, porém sem ameaças à vida; e apenas um motociclista com classificação 4, apresentando lesões graves com ameaça à vida.

Em relação aos traumatismos sofridos em membros e cintura pélvica, locais mais atingidos, observase que a maioria dos acidentes $(53,3 \%, \mathrm{n}=234)$ levaram os motociclistas a traumatismos de gravidade CAIS 85 2-moderada (Tabela 1).

Foram estabelecidas ainda as categorias de comprometimentos funcionais que as deficiências motoras adquiridas causaram, a partir da Classificação Internacional de Funcionalidade, Incapacidade e Saúde (CIF). Para que fosse realizada a classificação de acordo com as categorias deste instrumento, foram analisados os comprometimentos funcionais neuromusculoesqueléticos dos motociclistas, associando-os às debilidades funcionais que se enquadravam em cada categoria da CIF. 
Entre os motociclistas que apresentaram deficiência motora como consequência dos acidentes de trânsito, puderam ser identificadas 4 categorias de comprometimentos funcionais: alteração na mobilidade das articulações; alteração na mobilidade dos ossos; alteração no padrão da marcha; e alteração na força muscular.

A alteração na mobilidade das articulações teve maior prevalência no grupo de motociclistas que apresentaram gravidade leve $(73,7 \%, \mathrm{n}=56)$. Pode-se ainda verificar por meio da análise dos dados que a prevalência desta deficiência motora diminui com o aumento da gravidade do trauma $(70,5 \%, n=165$ para o grupo com gravidade moderada, 50,8\%, $n=61$ para o grupo grave - sem ameaça a vida e $44,4 \%, n$ = quatro, para grave - com ameaça a vida). O teste de independência foi significativo ( $p$-valor $<0,001)$, indicando que a gravidade da lesão é determinante para a alteração na mobilidade das articulações (Tabela 2).

Tabela 2 - Distribuição da alteração na mobilidade das articulações segundo a gravidade da lesão ( $\mathrm{n}=439)$. Recife, PE, Brasil, 2016

\begin{tabular}{lccc} 
Gravidade da lesão dos motociclistas & \multicolumn{2}{c}{$\begin{array}{c}\text { Alteração na mobilidade das } \\
\text { articulações (b710) }\end{array}$} & \multirow{2}{*}{ p-valor } \\
\cline { 2 - 3 } & Sim N(\%) & Não N(\%) & \\
\hline Leve & $56(73,7)$ & $20(26,3)$ \\
\hline Moderada & $165(70,5)$ & $69(29,5)$ & \multirow{2}{*}{$<0,001^{1}$} \\
\hline Grave - sem ameaça a vida & $61(50,8)$ & $59(49,2)$ &
\end{tabular}

${ }^{1} p$-valor do teste Qui-quadrado para independência (se p-valor $<0,05$ a gravidade da lesão influencia significativamente na alteração na mobilidade das articulações).

A distribuição da alteração na mobilidade óssea segundo a gravidade da lesão mostrou que esse comprometimento foi mais prevalente no grupo de motociclistas que apresentaram risco grave - com ameaça a vida (88,9\%, $\mathrm{n}=$ oito), como pode ser constatado na Tabela 3. Observou-se ainda que a prevalência desta deficiência motora aumenta de acordo com o aumento da gravidade da lesão $(42,1 \%$, $\mathrm{n}=32$ para o grau leve, 59,4\%, $\mathrm{n}=139$ para o grau moderado e $65,0 \%, \mathrm{n}=78$ para o grau grave - sem ameaça a vida). Além disso, o teste de independência foi significativo ( $p$-valor $=0,003$ ), indicando que a gravidade da lesão foi determinante para a alteração na mobilidade óssea.

Tabela 3 - Distribuição da alteração na mobilidade óssea segundo a gravidade da lesão ( $\mathrm{n}=439)$. Recife, PE, Brasil, 2016

\begin{tabular}{|c|c|c|c|}
\hline \multirow[t]{2}{*}{ Gravidade da lesão dos motociclistas } & \multicolumn{2}{|c|}{$\begin{array}{c}\text { Alteração na mobilidade óssea } \\
\text { (b720) }\end{array}$} & \multirow{2}{*}{ p-valor } \\
\hline & $\operatorname{Sim} \mathbf{N}(\%)$ & Não N(\%) & \\
\hline Leve & $32(42,1)$ & $44(57,9)$ & \multirow{4}{*}{$0,003^{1}$} \\
\hline Moderada & $139(59,4)$ & $95(40,6)$ & \\
\hline Grave - sem ameaça a vida & $78(65)$ & $42(35)$ & \\
\hline Grave - com ameaça a vida & $8(88,9)$ & $1(11,1)$ & \\
\hline
\end{tabular}

${ }^{1} \mathrm{p}$-valor do teste exato de Fisher (se p-valor $<0,05$ a gravidade da lesão influencia significativamente na alteração de mobilidade óssea). 
Na Tabela 4 tem-se a distribuição da alteração no padrão da marcha segundo a gravidade da lesão. Verifica-se que este tipo de deficiência motora foi mais prevalente no grupo de vitimados que apresentaram risco grave - com ameaça a vida $(77,8 \%, \mathrm{n}=$ sete). Ainda, a prevalência deste comprometimento motor aumenta juntamente com o aumento da gravidade do trauma. Além disso, o teste de independência foi significativo ( $p$-valor $<0,001$ ), indicando forte influência da gravidade das lesões na alteração no padrão da marcha.

Tabela 4 - Distribuição da alteração no padrão da marcha segundo a gravidade da lesão ( $n=439)$. Recife, PE, Brasil, 2016

\begin{tabular}{lccc} 
Gravidade da lesão dos motociclistas & \multicolumn{2}{c}{$\begin{array}{c}\text { Alteração no padrão da } \\
\text { marcha (b770) }\end{array}$} & p-valor \\
\cline { 2 - 3 } & Sim N(\%) & $\mathbf{N a ̃ o} \mathbf{N}(\%)$ & \\
\hline Leve & $6(7,9)$ & $70(92,1)$ \\
\hline Moderada & $53(22,6)$ & $181(77,4)$ & \multirow{2}{*}{$<0,0011$} \\
\hline Grave - sem ameaça a vida & $59(49,2)$ & $61(50,8)$ &
\end{tabular}

${ }^{1} \mathrm{p}$-valor do teste Qui-quadrado para independência (se p-valor $<0,05$ a gravidade da lesão influencia significativamente na alteração do padrão da marcha).

E por fim, na Tabela 5 temos a distribuição da alteração na força muscular segundo a gravidade da lesão. Esta deficiência motora foi mais prevalente no grupo de motociclistas que apresentaram lesões graves - com ameaça a vida $(33,3 \%, \mathrm{n}=$ três). Ainda, observa-se que a prevalência deste comprometimento aumenta de acordo com o aumento da gravidade do trauma $(3,9 \%, \mathrm{n}=$ três para o grau leve, 8,1\%, $\mathrm{n}=19$ para o grau moderado e 13,3\%, $\mathrm{n}=16$ para o grau grave - sem ameaça a vida). Mesmo sendo encontrada essa relação, o teste de independência não foi significativo ( $p$-valor $=0,010)$, indicando que não podemos aceitar a existência dessa relação nesta pesquisa.

Tabela 5 - Distribuição da alteração na força muscular segundo a gravidade da lesão ( $n=439)$. Recife, PE, Brasil, 2016

\begin{tabular}{lccc} 
Gravidade da lesão dos motociclistas & \multicolumn{2}{c}{$\begin{array}{c}\text { Alteração na força muscular } \\
\text { (b730) }\end{array}$} & \multirow{2}{*}{ p-valor } \\
\cline { 2 - 3 } & \multicolumn{2}{c}{$\begin{array}{c}\text { Sim } \mathbf{N}(\%) \\
\text { Não N(\%) }\end{array}$} & \\
\hline Leve & $3(3,9)$ & $73(96,1)$ \\
\hline Moderada & $19(8,1)$ & $215(91,9)$ & \multirow{2}{*}{$0,010^{1}$} \\
\hline Grave - sem ameaça a vida & $16(13,3)$ & $104(86,7)$ & \\
\hline Grave - com ameaça a vida & $3(33,3)$ & $6(66,7)$ &
\end{tabular}

${ }^{1} \mathrm{p}$-valor do teste Qui-quadrado para independência (se p-valor $<0,05$ a gravidade da lesão influencia significativamente na alteração na força muscular).

\section{- DISCUSSÃO}

O número de 439 pessoas que apresentaram algum tipo de deficiência motora motivadas pelos acidentes com motocicletas é bastante significativo e alarmante. Acredita-se que, se forem consideradas todas as vítimas envolvidas, e também os que foram periciados em outros institutos e estabelecimentos 
de saúde, os números seriam mais elevados e preocupantes.

O quantitativo de registros de segmentos corporais afetados por traumatismos foi superior ao quantitativo da amostra, permitindo assim afirmar que um mesmo motociclista pode apresentar diferentes estruturas anatômicas lesionadas. A identificação dos membros inferiores como as áreas corporais mais comumente afetadas é algo frequente entre as investigações científicas com o público dos motociclistas ${ }^{(5-6,8,11-13)}$. Essa constatação é fundamentada na ausência de mecanismos protetores para esses segmentos corporais, o que os tornam mais expostos aos traumas no momento do acidente.

A prevalência das fraturas do tipo fechada se assemelha aos dados de outros estudos ${ }^{(5-6,8,13)}$, e pode estar relacionada ao tempo necessário para tratamento e consolidação das fraturas, por meio das imobilizações, que muitas vezes é extenso, acarretando longos períodos de internamento e recuperação das vítimas.

No que se refere à classificação das gravidades dos traumas sofridos pelos motociclistas, observouse que a prevalência da gravidade moderada também foi a mais encontrada em motociclistas analisados por outras investigações ${ }^{(6,14)}$. A constatação de que as lesões que estão produzindo deficiências motoras nos motociclistas são as de gravidade moderada, que não acarretam em risco à vida, faz perceber que a grande maioria dessas deficiências poderia ser prevenida ou evitada.

Foram estabelecidas ainda, com base nos laudos periciais dos motociclistas analisados, as categorias dos comprometimentos funcionais neuromusculoesqueléticos, a partir da Classificação Internacional de Funcionalidade, Incapacidade e Saúde (CIF). Vale salientar que, no Brasil, não existe uma padronização na avaliação pericial em relação à utilização deste instrumento, ficando a classificação dos tipos de incapacidades a critério do médico perito ${ }^{(15)}$.

A alteração na mobilidade das articulações foi o comprometimento funcional causado pelas deficiências motoras mais prevalente entre os motociclistas analisados. Relacionando este tipo de comprometimento motor com a gravidade das lesões sofridas, pôde-se verificar que os motociclistas com gravidade CAIS 851 - leve, adquiriram de forma mais prevalente limitação na mobilidade das articulações, e que a prevalência desta limitação motora diminui com o aumento da gravidade do trauma.

Assim sendo, por menor que sejam os agravos envolvidos em uma ocorrência de trânsito com motocicletas, é possível que deles resultem algum tipo de comprometimento motor. É possível concluir também que, à medida em que a gravidade do trauma aumenta, diminuem as possibilidades de alterações na mobilidade das articulações, porém, isso não exclui a possibilidade da ocorrência de outros tipos de limitações motoras.

O segundo comprometimento motor mais prevalente foi a alteração na mobilidade dos ossos, caracterizado pela redução na amplitude dos movimentos dos $\operatorname{ossos}^{(10)}$. A presença desta limitação funcional pode ser explicada pelo alto percentual de fraturas encontradas nos motociclistas. Segundo a gravidade da lesão, a alteração na mobilidade dos ossos foi mais prevalente no grupo de motociclistas que apresentaram CAIS 854 - grave com ameaça a vida (88,9\%), e a prevalência desta deficiência motora aumentou de acordo com o aumento da gravidade da lesão.

A alteração no padrão da marcha nos motociclistas analisados provavelmente está relacionada às lesões em membros inferiores, que foram os segmentos corporais mais acometidos. Este tipo de deficiência motora prevaleceu no grupo de vitimados que apresentaram risco grave - com ameaça a vida $(77,8 \%, \mathrm{n}=$ sete), e a prevalência deste comprometimento aumentou juntamente com o aumento da gravidade do trauma.

Por fim, a alteração na força muscular, comprometimento encontrado em menor quantitativo $(9,3 \%, n=41)$, caracterizado por um déficit na força gerada pela contração muscular(10), ocasionada provavelmente em decorrência também do tempo prolongado de imobilização dos membros. Verificouse que este tipo de deficiência foi mais prevalente no grupo de motociclistas que apresentaram lesões graves com ameaça a vida (33,3\%, $\mathrm{n}=$ três), e que a prevalência deste comprometimento aumentou de acordo com o aumento da gravidade do trauma. Porém, o teste de independência aplicado para avaliação desta relação não foi significativo, indicando que, nesta pesquisa, não se pode aceitar a relação existente entre a gravidade do trauma e o comprometimento da força muscular, concluindo-se 
dessa forma que a ocorrência desta limitação pode existir em qualquer gravidade de trauma.

Dentre os quatro tipos de comprometimentos neuromusculoesqueléticos encontrados nesta pesquisa, três prevaleceram nos motociclistas com score de gravidade do trauma 4 - grave com ameaça a vida, a saber, alteração na mobilidade dos ossos, alteração no padrão da marcha e alteração na força muscular. Esta constatação permite inferir que, quanto mais grave forem as lesões e as injúrias traumáticas sofridas pelos motociclistas, maiores serão as possibilidades de limitações funcionais motoras.

Como limitações deste estudo, destaca-se a não inclusão de todas as vítimas envolvidas em acidentes de trânsito com motocicletas, o que poderia ampliar o conhecimento da gravidade dos traumas sofridos, dos comprometimentos funcionais e das deficiências motoras que atingem esta população.

\section{- CONCLUSÃo}

Os resultados desta pesquisa evidenciaram que, independente da gravidade do trauma sofrido, todos podem acarretar em comprometimentos funcionais que produzirão deficiências motoras, e que um mesmo indivíduo pode apresentar mais de um tipo de comprometimento motor, uma vez que diferentes segmentos corporais podem ser atingidos durante o acidente.

Considerando a gravidade dos acidentes envolvendo motocicletas e sua relação com os tipos de comprometimento funcional encontrados nessa pesquisa, pôde-se concluir que, na grande maioria dos casos, as limitações motoras que os motociclistas apresentaram estiveram diretamente associadas com o tipo de gravidade do acidente. Esse conhecimento é imprescindível para elaboração de novas estratégias de fiscalização e punição às infrações, bem como de medidas educativas e preventivas no trânsito.

Os achados desta pesquisa permitem que se tenha uma dimensão da magnitude da problemática dos acidentes de trânsito envolvendo motociclistas, e da necessidade de estratégias preventivas e de promoção da saúde, não apenas pelo Estado, mas também pelo setor saúde e pela sociedade, principalmente porque grande parte dos comprometimentos motores possui caráter evitável.

Cabe ressaltar também que, por si só, as informações relacionadas às deficiências motoras adquiridas pelos motociclistas vítimas de acidentes de trânsito não são suficientes para descrever as condições de saúde dos indivíduos acometidos, nem os impactos que elas produzem. São necessárias informações que permitam uma visão mais completa tanto dos fatores envolvidos nos acidentes de trânsito, como dos efeitos que as deficiências motoras provocam na vida dos vitimados.

O conhecimento sobre os acidentes de trânsito com motocicletas, seus fatores determinantes, e os agravos que incidem sobre a saúde da população é primordial para a criação de mecanismos que reduzam as situações de vulnerabilidade, e consequentemente da ocorrência dos casos de deficiências.

\section{- REFERÊNCIAS}

1. Cruz MJA. Os impactos dos acidentes de trânsito por lesão corporal na vida dos vitimados em face ao controle social do Estado [dissertação]. Belém (AM): Universidade da Amazônia, Programa de Mestrado em Desenvolvimento e Meio Ambiente Urbano; 2013.

2. Ganne N. Estudo sobre acidentes de trânsito envolvendo motocicletas na Cidade de Corumbá e região, Estado do Mato Grosso do Sul, Brasil, no ano de 2007. Rev. Pan-AmazonicaSaud [Internet]. 2010 [acesso em 2017 ago27];1(3). Disponível em: http://scielo.iec.gov.br/pdf/rpas/v1n3/v1n3a03.pdf.

3. Pligher FA. Arte, Mito e Tecnologia: a motocicleta como fenômeno cultural do século XX [dissertação]. São Paulo (SP): Universidade Estadual de Campinas, Programa de Mestrado em Artes; 2006.

4. Rocha GS, Schor N. Acidentes de motocicleta no município de Rio Branco: caracterização e tendências. Cienc. saude colet.[Internet] 2013;18(3) [acesso em 20 out 2017]. Disponível: http://dx.doi.org/10.1590/S141381232013000300018. 
5. Ascari RA, Chapieski CM, da Silva OM, Frigo J. Perfil epidemiológico de vítimas de acidentes de trânsito. Rev. Enferm. UFSM. [Internet].2013 [acesso em 2017 set 28];3(1). Disponível em:http://dx.doi.org/10.5902/217976927711.

6. Macedo APFS, Oliveira LR, Buchalla CM, Scatena JHG. Características e deficiências físicas de vítimas de acidentes de trânsito atendidas no serviço de referência para reabilitação do estado de Mato Grosso, Brasil, 2010. Revista Espaço para a Saúde [Internet] 2014;15(4) [acesso em 27 Abr 2016]. Disponível: http://www.uel.br/revistas/ uel/index.php/espacoparasaude/article/view/18733/pdf_44.

7. Pinto AO, Witt RR. Gravidade de lesões e características de motociclistas atendidos em um hospital de pronto socorro. Rev. Gaúcha Enferm. [Internet]. 2008 [acesso em 2017 out 20];29(3). Disponível em: http://www.lume. ufrgs.br/handle/10183/23604.

8. Seguradora Líder. Administradora de anos pessoais causados por veículos automotores de via terrestre. Anuário Estatístico 2014 [Internet]. 2014 [acesso em 2017 set 28]. Disponível em: https://www.seguradoralider. com.br/Documents/boletim-estatistico/Anuario-Estatistico-2014-DPVAT.pdf.

9. Sallum AMC, Koizumi MS. Natureza e gravidade das lesões em vítimas de acidente de trânsito de veículo a motor.Rev. Esc. Enferm. USP.[Internet]. 1999 [acesso em 2017 ago27];33(2). Disponível em:http://dx.doi. org/10.1590/S0080-62341999000200007.

10. Organização Mundial de Saúde (OMS). Direção Geral da Saúde. Como usar a CIF: um manual prático para o uso da Classificação Internacional de Funcionalidade, Incapacidade e Saúde (CIF). [Internet] Genebra: OMS; 2013 [acesso em 2017 set 17]. Disponível em: http://www.fsp.usp.br/cbcd/wp-content/uploads/2015/11/ManualPratico-da-CIF.pdf.

11. Berger PP. Estudo dos acidentes com motocicletas e da gravidade das lesões decorrentes [dissertação]. Vitória (ES):Universidade Federal do Espírito Santo, Programa de Pós-graduação em Engenharia Civil; 2014.

12. Mascarenhas CHM, Azevedo LM, Novaes VS. Lesões musculoesqueléticas em motociclistas vítimas de acidentes de trânsito. Rev. Ciênc. Desenvolvimento.[Internet]. 2010 [acesso em 2017out 20];3(1). Disponível em: http://srv02.fainor.com.br/revista/index.php/memorias/article/view/79/70.

13. Costa FGMF, Silva LM, Correia RA, Furtado BMASM,Bonfim CV. Characterization of motorcycle accident victims attended by the mobile emergency service (SAMU - 192), Recife, Pernambuco State, Brazil. Health Sci Acta Sci. [Internet]. 2012 [acessoem 2017 set 17];34. Disponível em: http://www.periodicos.uem.br/ojs/index.php/ ActaSciHealthSci/article/view/11524/pdf.

14. Duarte ML,Souza ECF, Bonfim PGF. Análise descritiva das sequelas de acidentes de trânsito em Maceió, Alagoas. Rev. Bras. Med. Fam. Comunidade. [Internet]. 2010 [acesso em 2017 jul17];5(17). Disponível em: https:// rbmfc.org.br/rbmfc/article/view/201.

15. Macedo APFS. A Classificação Internacional de Funcionalidade, Incapacidade e Saúde (CIF) e a deficiência física em vítimas de acidentes de transporte [dissertação]. Cuiabá (MT): Universidade Federal do Mato Grosso, Programa de Pós-Graduação em Saúde Coletiva; 2011. 